\title{
Acetylcholinesterase - Choline Oxidase Biosensor for Pirimicarb Determination
}

\author{
S.C.A. Sousa, M.J.F. Rebelo* \\ CCMM -Faculdade de Ciências da Universidade de Lisboa, Campo Grande, C 8 \\ 1749-016 Lisboa, Portugal
}

Received $29^{\text {th }}$ June 2007; accepted $27^{\text {th }}$ September 2007

\begin{abstract}
A biosensor for the determination of pirimicarb was constructed by the coimmobilization of acetylcholinesterase and choline oxidase on a derivatised polyethersulfone membrane. The membrane was applied to an Universal Sensors electrode base system and the hydrogen peroxide formation was monitored upon addition of acetylcholine to an appropriately chosen buffer where the biosensor was dipped.

The hydrogen peroxide is the product of the hydrolysis of choline, catalysed by cholineoxidase. Choline was formed by the action of acetylcholinesterase on acetylcholine. Pirimicarb inhibits these reactions and that fact can be used to determine its concentration. A calibration plot for pirimicarb was obtained.
\end{abstract}

Keywords: acetylcholine, biosensor, pirimicarb, acetylcholinesterase, polyethersulfone.

\section{Introdução}

Biossensor

Um biossensor é um dispositivo analítico compacto, que incorpora um elemento bio-sensível, integrado com um sistema transdutor. O princípio de detecção é a "ligação" selectiva do analito de interesse ao elemento complementar de bio reconhecimento imobilizado num suporte adequado. A interacção resulta na alteração de uma ou mais propriedades físico-químicas (alteração de $\mathrm{pH}$, transferência de electrões, alteração de massa, transferência de calor, libertação de gases ou iões) que são detectadas e que podem ser medidas pelo transdutor. $\mathrm{O}$ principal objectivo é produzir um sinal electrónico que é proporcional em

\footnotetext{
* Corresponding author. E-mail address: mjrebelo@fc.ul.pt
} 
magnitude ou frequência à concentração de um determinado analito ou grupo de analitos que interagem com o elemento bio-sensível.

Os biossensores podem ser classificados pelo seu sistema de bio reconhecimento. Os mais importantes materiais biológicos usados na tecnologia dos biossensores são os pares enzima/substrato, anticorpo/antigene e ácidos nucleicos/sequências complementares [1].

Os elementos biológicos são geralmente imobilizados em suportes apropriados para manter a sua actividade. As técnicas de imobilização de enzimas podem ser classificadas em:

(1) retenção por uma membrana inerte;

(2) adsorção física numa interface sólida;

(3) ligações cruzadas com agentes bifuncionais;

(4) oclusão em matrizes poliméricas;

(5) ligação covalente num suporte funcionalizado.

Mecanismo de transdução electroquímico: detecção amperométrica

Os biossensores com detecção amperométrica são os mais comuns [2]. Nos biossensores amperométricos produz-se corrente quando um potencial fixo é aplicado entre dois eléctrodos. O sistema fundamental de medição é composto por três eléctrodos: um eléctrodo de trabalho, onde a reacção desejada ocorre, um eléctrodo de referência e um eléctrodo auxiliar. Na prática, no entanto, dois eléctrodos, o de trabalho e pseudo-referência, podem ser suficientes, uma vez que as correntes envolvidas são muito pequenas (da ordem dos $\mathrm{nA}$, no caso presente). O potencial aplicado usado deve ser optimizado para a molécula específica em estudo. A maior vantagem da técnica amperométrica é o baixo custo e a elevada reprodutibilidade destes eléctrodos que elimina a necessidade de repetidas calibrações. Limitações desta técnica incluem as interferências de compostos electroactivos [3].

\section{Inibição}

Os estudos da inibição, in vivo e in vitro, de reacções enzimáticas têm contribuído para o importante conhecimento de vários campos da bioquímica. Por exemplo, o mecanismo de acção de muitas substâncias tóxicas e antídotos afectam directamente as enzimas. Em muitos casos tem sido revelada a importância destas enzimas para o metabolismo. Por outro lado, a descoberta de produtos finais de inibição elucidou muitos caminhos metabólicos. A inibição enzimática pode ser reversível ou irreversível.

\section{Pesticidas}

Os pesticidas são substâncias usadas para prevenir ou reduzir a proliferação de pragas, como por exemplo, insectos, micróbios, roedores, algas, peixes, plantas, etc. O uso mais comum dos pesticidas é na agricultura e na jardinagem.

Alguns temas preocupantes quando se trabalha com pesticidas incluem a contaminação ambiental e a falta de selectividade [4]. 


\section{Inibição da acetilcolinesterase}

\section{Função da acetilcolina}

Tanto os organofosforatos como os carbamatos actuam na inibição da enzima acetilcolinesterase, que catalisa a hidrólise da acetilcolina a colina e acetato. A acetilcolina é um neurotransmissor sintetizado pela célula transmissora ou présináptica. Ela é armazenada em vesículas sinápticas até que um potencial de acção leve a uma despolarização da membrana plasmática das células présinápticas. Isto resulta na entrada de $\mathrm{Ca}^{2+}$ seguida pela fusão de vesículas sinápticas com a membrana plasmática. A acetilcolina é libertada na fenda sináptica e difunde-se até ao receptor, a célula pós-sináptica. Aqui, a acetilcolina liga-se ao seu receptor, que pode actuar como um canal catiónico. O receptor sofre uma mudança conformacional logo após a ligação à acetilcolina. Esta mudança na estrutura tridimensional resulta na entrada de $\mathrm{Na}^{+}$que despolariza a membrana plasmática na célula pós-sináptica. Tem início um potencial de acção. É necessário que a acetilcolina seja removida da fenda sináptica antes que a sinapse seja capaz de responder a outro sinal. Isto requer a acção da acetilcolinesterase, que catalisa a reacção de hidrólise da acetilcolina produzindo colina e acetato. A colina é absorvida pelas células pré-sinápticas e usada na síntese de mais acetilcolina. $\mathrm{O}$ acetato é transportado para outros tecidos $\mathrm{e}$ metabolizado.

\section{A catálise pela acetilcolinesterase}

As enzimas são catalisadores biológicos. Como tais, aumentam a velocidade de uma reacção química sem serem consumidos. A maioria das enzimas é altamente específica em relação à reacção a ser catalisada. Assim, a acetilcolinesterase catalisa a reacção de hidrólise da acetilcolina formando colina e acetato, como se indica nas Fig. 1 e 2, estando explicitada na Fig. 2 a acção do centro activo da enzima neste processo.
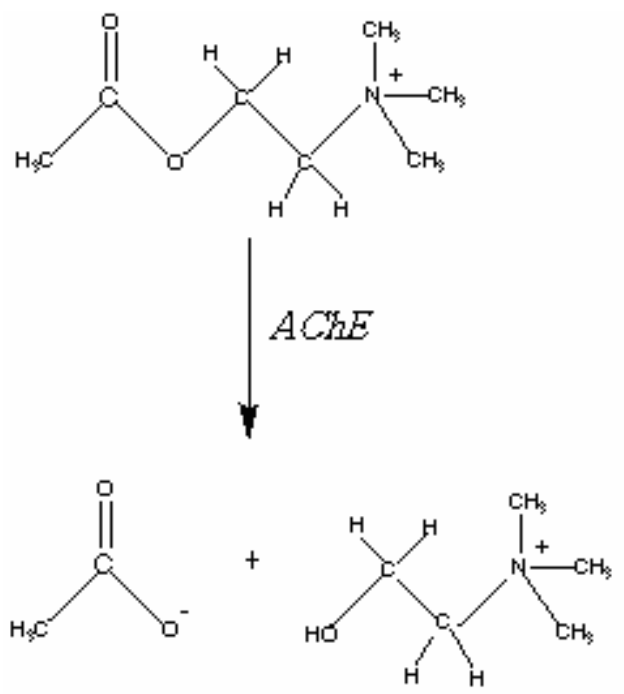

Figura 1. Acetilcolina dando origem a colina e acetato por acção da enzima acetilcolinesterase. 
O diagrama abaixo mostra a ligação da acetilcolina ao centro activo da acetilcolinesterase e a respectiva catálise:

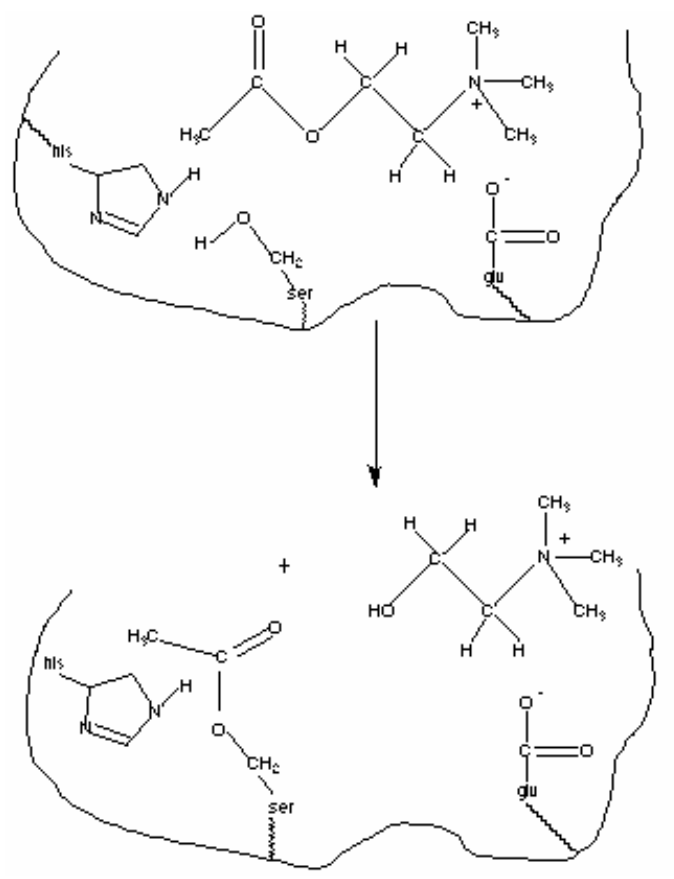

Figura 2. Ligação da acetilcolina ao centro activo da acetilcolinesterase e a respectiva catálise.

Esta acção pode ser inibida por substâncias que se ligam ao centro activo da AChE. É o que acontece, por exemplo, com os carbamatos. A Fig. 3 apresenta um diagrama de um carbamato, ligado covalentemente a um fragmento de serina no centro activo da acetilcolinesterase.

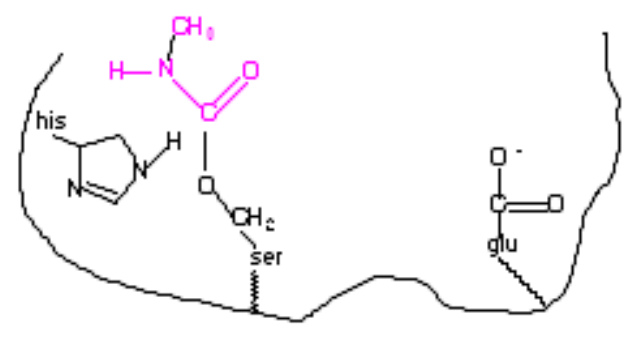

Figura 3. Carbamato ligado covalentemente a um fragmento de serina no centro activo da AChE.

A toxicidade aguda destas espécies é devida ao seu efeito causado no sistema nervoso dos animais [5]. 


\section{Pirimicarbo}

O carbamato testado nesta actividade experimental foi o pirimicarbo, que é usado como insecticida. O nome IUPAC deste composto é o 2-dimetilamino-5,6dimetilpirimidino-4-il dimetilcarbamato. A sua estrutura está representada na Fig. 4.

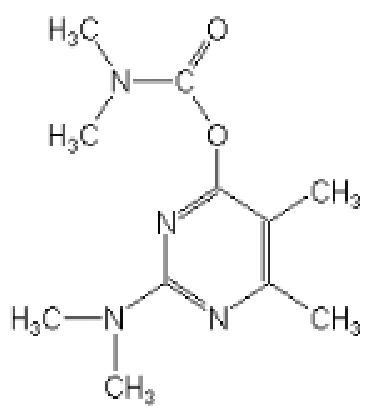

Figura 4. Estrutura do pirimicarbo $\left(\mathrm{C}_{11} \mathrm{H}_{18} \mathrm{~N}_{4} \mathrm{O}_{2}\right)$.

Como já se disse, a enzima $\mathrm{AChE}$ catalisa a reacção da $\mathrm{ACh}$ com água, formando assim colina e acetato. O pirimicarbo inibe a acção da $\mathrm{AChE}$, diminuindo a produção dos produtos anteriormente referidos. Mas como é que se detecta o grau de inibição, bem como a quantidade de produtos formados? A colina, um dos produtos formados, é oxidada pelo oxigénio, formando-se o betaína-aldeído e o peróxido de hidrogénio. Esta reacção é catalisada pela enzima colina oxidase,

$$
\left(\mathrm{CH}_{3}\right)_{3} \mathrm{~N}^{+} \mathrm{CH}_{2} \mathrm{CH}_{2} \mathrm{OH}+\mathrm{O}_{2} \stackrel{\mathrm{ChOx}}{\longrightarrow}\left(\mathrm{CH}_{3}\right)_{3} \mathrm{~N}^{+} \mathrm{CH}_{2} \mathrm{CHO}+\mathrm{H}_{2} \mathrm{O}_{2}
$$

A formação de $\mathrm{H}_{2} \mathrm{O}_{2}$ foi quantificada, usando um eléctrodo de detecção de peróxido de hidrogénio.

\section{Parte Experimental}

\section{Reagentes}

Para a determinação amperométrica utilizaram-se as enzimas acetilcolinesterase (da Electrophorus electricus (electric eel) Type V-S (EC.3.1.1.7), colina oxidase (EC.1.1.3.17, $14 \mathrm{U} / \mathrm{mg}$ ), e como substratos utilizou-se acetilcolina (acetylcholine chloride, $\mathrm{C}_{7} \mathrm{H}_{16} \mathrm{NO}_{2} \mathrm{Cl}, \mathrm{M}_{\mathrm{r}}$ 181.66, de pureza superior a 99.0\%) e colina (choline chloride, $\mathrm{C}_{5} \mathrm{H}_{14} \mathrm{NOCl}, \mathrm{M}_{\mathrm{r}} 139,63$ de pureza superior a 99.0\%), fornecidos pela Sigma. O pirimicarbo $\left(\mathrm{C}_{11} \mathrm{H}_{18} \mathrm{~N}_{4} \mathrm{O}_{2}, \mathrm{M}_{\mathrm{r}} 238.286\right.$, de pureza superior a $\left.99.5 \%\right)$ foi fornecido pela Chem Service.

Os tampões utilizados foram: fosfato $(0,1 \mathrm{M} \mathrm{e} \mathrm{pH}=7)$, preparado a partir de $8.4394 \mathrm{~g}$ de fosfato de potássio $\left(\mathrm{KH}_{2} \mathrm{PO}_{4}, \mathrm{M}_{\mathrm{r}} 136.1\right.$, de pureza superior a $\left.99.7 \%\right)$ e $5.3976 \mathrm{~g}$ de fosfato de sódio $\left(\mathrm{Na}_{2} \mathrm{HPO}_{4}, \mathrm{M}_{\mathrm{r}} 142.0\right.$ de pureza superior a $\left.99.9 \%\right)$, ambos fornecidos pela Sigma ; e PBS (phosphate buffer saline), preparado a partir de $4.9673 \mathrm{~g}$ de cloreto de sódio $\left(\mathrm{NaCl}, \mathrm{M}_{\mathrm{r}} 58.44\right.$, de pureza superior a 99.8\%) fornecido pela Riedel-de Haën, $0.123 \mathrm{~g}$ de cloreto de potássio $\left(\mathrm{KCl}, \mathrm{M}_{\mathrm{r}}\right.$ 74.56) fornecido pela Fluka, $0.678 \mathrm{~g}$ de fosfato de sódio $\left(\mathrm{Na}_{2} \mathrm{HPO}_{4}, \mathrm{M}_{\mathrm{r}} 142.0\right.$, de 
pureza superior a 99.9\%) fornecido pela Sigma e $0.1224 \mathrm{~g}$ de fosfato de potássio. Perfez-se o volume do tampão fosfato até $1 \mathrm{~L}$, enquanto que da solução PBS se perfez até $500 \mathrm{~mL}$ com água Millipore. Para o ajuste do $\mathrm{pH}$ das soluções tampão preparadas recorreu-se ao hidróxido de potássio $\left(\mathrm{KOH}, \mathrm{M}_{\mathrm{r}}\right.$ 56.11) fornecido pela Riedel-de Haën.

\section{Instrumentação}

As pesagens foram todas efectuadas numa balança Mettler Toledo AX205 $(\mathrm{d}=0.01 \mathrm{mg})$. As amostras em estudo foram agitadas numa placa de agitação AGIMATIC-N P SELECTA.

O sistema base de eléctrodos utilizado na determinação amperométrica é da Universal Sensors (New Orleans, LA), composto por um eléctrodo de discos de platina de $0.3 \mathrm{~mm}$ de diâmetro e um eléctrodo de referência $\mathrm{Ag} / \mathrm{AgCl}$, que servia simultaneamente de eléctrodo auxiliar, uma vez que as correntes envolvidas são da ordem de nA. O electrólito interno deste sistema de eléctrodos era o PBS. O Amperometric Biossensor Detector, da Universal Sensor Inc., forneceu o potencial aplicado ao biossensor e mediu os valores amperométricos resultantes da acção da enzima sobre o substrato. Os registos destes mesmos valores foram efectuados pelo registador Recorder REC102 da Pharmacia Biotech.

As medições das soluções foram realizadas por micropipetas Finnpipette Digital ACL, da Labsystems, de capacidade 40-200 $\mu \mathrm{L}$ e 10-40 $\mu \mathrm{L}$.

A imobilização das enzimas foi efectuada em membranas GELM66544, da Ultrabind, constituídas por polietersulfona modificada com grupos aldeído e com uma espessura de $152 \mu \mathrm{m}$ com poros de $0.45 \mu \mathrm{m}$.

\section{Procedimento experimental}

Acção da colina oxidase na colina

Dissolveram-se $0.3 \mathrm{mg}$ da enzima colina oxidase em $30 \mu \mathrm{L}$ de tampão fosfato (Ph) de $\mathrm{pH} 7$, colocando-a posteriormente numa membrana a imobilizar durante 2 horas. Preparou-se uma solução de colina $(\mathrm{Ch})$ de concentração $10^{-3} \mathrm{M} \mathrm{em}$ tampão fosfato de $\mathrm{pH}$ 7. Colocou-se o eléctrodo em $5 \mathrm{~mL}$ de tampão fosfato e adicionaram-se a este $50 \mu \mathrm{L}$ da solução de $\mathrm{Ch}$ de modo a testar o eléctrodo. $\mathrm{O}$ mesmo procedimento foi realizado quando se testou o eléctrodo, colocando agora uma membrana limpa neste. Após as 2 horas colocou-se a membrana com a enzima imobilizada no eléctrodo e deixou-se a estabilizar durante cerca de 5 minutos numa solução nova de tampão fosfato. Após a estabilização, adicionaram-se $50 \mu \mathrm{L}$ da solução $\mathrm{Ch}$. Repetiu-se o procedimento relatado anteriormente com a excepção de que se preparou a solução de $\mathrm{Ch}$ de concentração $10^{-2} \mathrm{M}$.

\section{Acção da acetilcolinesterase e colina oxidase na acetilcolina}

Pesaram-se $0.3 \mathrm{mg}$ das enzimas ChOx e AChE e dissolveu-se cada uma em 30 $\mu \mathrm{L}$ de tampão fosfato de $\mathrm{pH} \mathrm{7,} \mathrm{colocando-as} \mathrm{posteriormente} \mathrm{numa} \mathrm{membrana} \mathrm{a}$ imobilizar durante 2 horas. Preparou-se uma solução de acetilcolina de 
concentração $10^{-2} \mathrm{M}$ em tampão fosfato de $\mathrm{pH}$ 7. Colocou-se o sistema de eléctrodos, apenas com a membrana interna, em $5 \mathrm{~mL}$ de tampão fosfato e adicionaram-se a este $50 \mu \mathrm{L}$ da solução de ACh de modo a testar o sistema de eléctrodos. O mesmo procedimento foi realizado, colocando agora uma membrana de poliétersulfona limpa no sistema de eléctrodos. Após as 2 horas colocou-se a membrana com as enzimas imobilizadas no sistema de eléctrodos e deixou-se a estabilizar durante cerca de 5 minutos numa solução nova de tampão fosfato. Após a estabilização, adicionaram-se $50 \mu \mathrm{L}$ da solução ACh.

Repetiu-se o procedimento relatado anteriormente com uma solução de ACh de concentração $2 \times 10^{-2} \mathrm{M}$.

\section{Resultados e Discussão}

Detecção do produto da reacção enzimática da acetilcolinesterase e colina oxidase

$\mathrm{Na}$ primeira etapa do trabalho estudaram-se as enzimas acetilcolinesterase e colina oxidase, nomeadamente a acção da primeira sobre um substrato, a acetilcolina. Imobilizando estas duas enzimas num sensor e entrando este em contacto com uma solução contendo o substrato acetilcolina sabe-se que primeiramente a acetilcolinesterase irá catalisar a hidrólise do substrato a colina. Por sua vez, a colina, na presença de colina oxidase e oxigénio, ir-se-á oxidar dando origem aos produtos betaína e peróxido de hidrogénio. Visto ter-se o peróxido de hidrogénio como um dos produtos finais, este pode ser monitorizado, recorrendo ao uso de um sensor amperométrico.

Aplicou-se um potencial de $400 \mathrm{mV}$ vs. $\mathrm{Ag} / \mathrm{AgCl}$ ao sistema de eléctrodos que se mergulhou em $5 \mathrm{~mL}$ de PBS, num vaso [este valor do potencial aplicado foi optimizado em trabalho anterior (M.J.F. Rebelo, A. M. L. Freitas), não publicado]. Manteve-se o sistema sob agitação com barra magnética e leu-se o valor da corrente estabilizada. Adicionaram-se, então, $25 \mu \mathrm{L}$ de $\mathrm{H}_{2} \mathrm{O}_{2}$ ao PBS e deixou-se novamente estabilizar a corrente, sendo a diferença entre os valores da corrente inicial e final, $\Delta \mathrm{I}$, devida à oxidação de $\mathrm{H}_{2} \mathrm{O}_{2}$. Fizeram-se adições sucessivas de $25 \mu \mathrm{L}$ de $\mathrm{H}_{2} \mathrm{O}_{2}$, lendo sempre o valor da corrente resultante. Os valores das correntes assim obtidas estão indicados na Tabela 1 e Fig. 5.

Seguidamente colocou-se no sistema base de eléctrodos uma membrana contendo a enzima colina oxidase, realizando depois o mesmo procedimento, desta vez fazendo adições sucessivas de $50 \mu \mathrm{L}$ de solução de colina $1 \times 10^{-2} \mathrm{M}$ a $5 \mathrm{~mL}$ de PBS. Os valores de $\Delta \mathrm{I}$ devidos à oxidação do $\mathrm{H}_{2} \mathrm{O}_{2}$, resultante da oxidação da colina, catalisada pela $\mathrm{ChOx}$ encontram-se na Tabela 2. Note-se que se fizeram testes em branco, só com o sistema base de eléctrodos e a membrana sem colina oxidase imobilizada e não se obteve resposta quando se adicionou a mesma quantidade de solução de colina $1 \times 10^{-2} \mathrm{M}$ a $5 \mathrm{~mL}$ de $\mathrm{PBS}$, confirmando assim a actividade da ChOx imobilizada. 
Tabela 1. Valores da corrente obtidos para a monitorização do peróxido de hidrogénio a um potencial aplicado de $400 \mathrm{mV}$ vs. $\mathrm{Ag} / \mathrm{AgCl}$.

\begin{tabular}{cc}
\hline \hline $\begin{array}{c}\text { Volume } \mathrm{H}_{2} \mathrm{O}_{2} \\
\text { adicionado } / \mu \mathrm{L}\end{array}$ & $\Delta \mathrm{I} / \mathrm{nA}$ \\
\hline \hline 25 & 7.2 \\
50 & 15.5 \\
75 & 23.1 \\
100 & 30.6 \\
125 & 38.2 \\
150 & 45.5 \\
175 & 52.6 \\
\hline
\end{tabular}

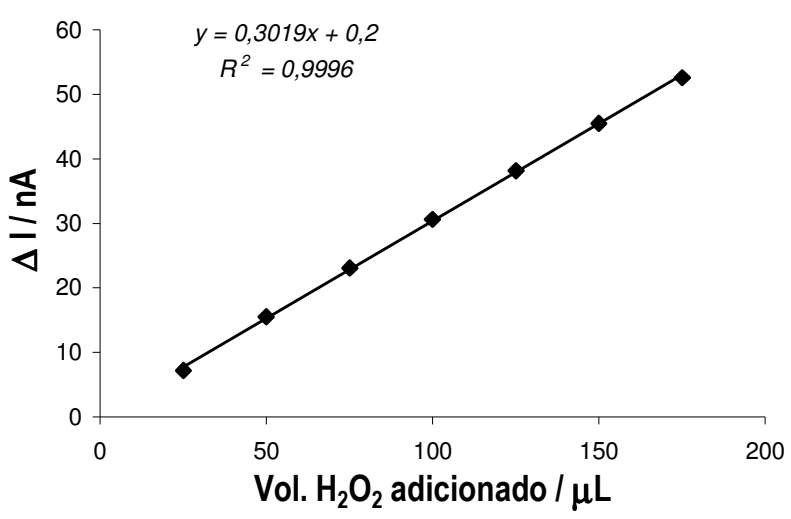

Figura 5. Variação da corrente detectada pelo sistema base de eléctrodos, em função do volume de $\mathrm{H}_{2} \mathrm{O}_{2}$ adicionado a $5 \mathrm{~mL}$ de PBS.

Tabela 2. Valores da corrente obtidos para o teste da membrana externa com ChOx a um potencial aplicado de $400 \mathrm{mV}$ vs. $\mathrm{Ag} / \mathrm{AgCl}$.

\begin{tabular}{cc}
\hline \hline $\begin{array}{c}\text { Volume solução de } \mathrm{Ch} 1 \times 10^{-2} \mathrm{M} \\
\text { adicionado/ } \mu \mathrm{L}\end{array}$ & $\Delta \mathrm{I} / \mathrm{nA}$ \\
\hline \hline 50 & 1.8 \\
100 & 3.4 \\
150 & 4.8 \\
200 & 5.7 \\
250 & 6.9 \\
300 & 7.5 \\
350 & 8.4 \\
400 & 9.6 \\
\hline
\end{tabular}

Com estes estudos prévios de resposta do sistema base de eléctrodos ao $\mathrm{H}_{2} \mathrm{O}_{2}$ e à colina, confirmou-se que se conseguia detectar a oxidação da colina, catalisada pela AcOx. 
Preparou-se então uma membrana nova com as enzimas $\mathrm{AChE}$ e $\mathrm{ChOx}$ e procedeu-se do modo habitual, desta vez com uma solução de ACh de concentração $2 \times 10^{-2} \mathrm{M}$. Após a obtenção dos resultados, testou-se a incubação do carbamato pirimicarbo de concentração $8 \times 10^{-6} \mathrm{M}$, deixando a membrana em contacto com este durante cerca de 1 hora. Os valores das correntes estabilizadas obtidos antes, $\mathrm{I}_{\mathrm{i}}$, e depois, $\mathrm{I}_{\mathrm{f}}$, de adicionar $50 \mu \mathrm{L}$ de acetilcolina $2 \times 10^{-2} \mathrm{M}$ a $5 \mathrm{~mL}$ de PBS em que mergulhava o biossensor com AchE e ChOx estão indicados na Tabela 3.

Tabela 3. Valores da corrente para as reacções das enzimas AchE e ChOx antes e após incubação com pirimicarbo de concentração $8 \times 10^{-6} \mathrm{M}$.

\begin{tabular}{ccccc}
\hline \hline $\begin{array}{c}\text { Potencial } \\
\text { aplicado vs. } \\
\mathrm{Ag} / \mathrm{AgCl} / \\
\mathrm{mV}\end{array}$ & $\begin{array}{c}\text { Volume de } \mathrm{ACh} \\
2 \times 10^{-2} \mathrm{M} \\
\text { adicionado } / \mu \mathrm{L}\end{array}$ & $\mathrm{I}_{\mathrm{i}} / \mathrm{nA}$ & $\mathrm{I}_{\mathrm{f}} / \mathrm{nA}$ & $\Delta \mathrm{I} / \mathrm{nA}$ \\
\hline 400 & 50 & 16.3 & 27.3 & 11 \\
\hline \hline
\end{tabular}

Após incubação com pirimicarbo $8 \times 10^{-6} \mathrm{M}$ (cerca de 1 hora)

$\begin{array}{lllll}400 & 50 & 17.9 & 18.4 & 0.5\end{array}$

Guardou-se uma membrana com as duas enzimas imobilizadas e estudou-se o seu tempo de vida. Verificou-se que as enzimas reduziram a sua actividade a $20 \%$ ao $2^{\circ}$ e $3^{\circ}$ dias, perdendo-a ao fim de 4 dias.

A membrana com as enzimas imobilizadas, que tinha sido incubada com o pirimicarbo perdeu completamente a actividade ao fim de $24 \mathrm{~h}$.

Fizeram-se testes análogos para várias concentrações do pirimicarbo $(1,2,4,6$ e $\left.8 \times 10^{-6} \mathrm{M}\right)$. Perante os resultados obtidos, calculou-se a percentagem de inibição da enzima AChE e ChOx sob a acção do carbamato pirimicarbo. Assim sendo, recorreu-se à seguinte expressão [6]:

$$
\% \text { inibição }=\left[\left(\Delta \mathrm{I}_{0}-\Delta \mathrm{I}_{\text {inib }}\right) / \Delta \mathrm{I}_{0}\right] \times 100
$$

em que $\Delta \mathrm{I}_{0}$ é o valor da corrente estabilizada que resulta da adição de acetilcolina $2 \times 10^{-2} \mathrm{M}$ a $5 \mathrm{~mL}$ de PBS em que o biossensor com as duas enzimas estava mergulhado antes da incubação com pirimicarbo. $\Delta \mathrm{I}_{\text {inib }}$ é o valor da corrente que resulta da adição de acetilcolina $2 \times 10^{-2} \mathrm{M}$ a $5 \mathrm{~mL}$ de PBS em que o biossensor com as duas enzimas estava mergulhado, após incubação com o carbamato. 
Obtiveram-se os valores de inibição da aceticolinesterase para diferentes concentrações de pirimicarbo $\left(1,2,4,6\right.$ e $\left.8 \times 10^{-6} \mathrm{M}\right)$, que estão indicados na Tabela 4.

Tabela 4. Valores da percentagem de inibição da acetilcolinesterase, para as concentrações de pirimicarbo utilizadas.

\begin{tabular}{cc}
\hline \hline Concentração de pirimicarbo / M & Percentagem de inibição / \% \\
\hline \hline $1 \times 10^{-7}$ & 34.61 \\
$1 \times 10^{-6}$ & 40.00 \\
$2 \times 10^{-6}$ & 54.05 \\
$4 \times 10^{-6}$ & 71.58 \\
$6 \times 10^{-6}$ & 74.38 \\
$8 \times 10^{-6}$ & 94.11 \\
\hline \hline
\end{tabular}

Verificou-se, portanto, que a percentagem de inibição pelo pirimicarbo era proporcional à concentração do mesmo.

Traduzindo os valores num gráfico, obteve-se a linha representada na Fig. 6.

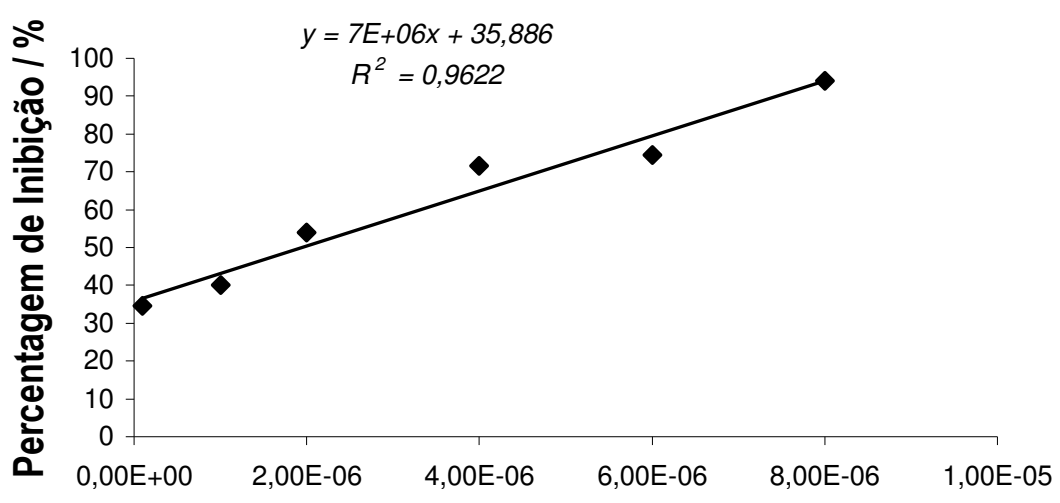

Concentração de Pirimicarbo / M

Figura 6. Relação entre percentagem de inibição e concentração do pirimicarbo.

\section{Conclusões}

Preparou-se um biossensor para o pirimicarbo por imobilização conjunta das enzimas acetilcolinesterase e colina oxidase em membranas de poliétersulfona derivada. As enzimas assim imobilizadas responderam à acetilcolina, observando-se uma corrente resultante quando se aplicou um potencial de +400 $\mathrm{mV}$ a um sistema base de eléctrodos a que se acoplou a referida membrana. Estas enzimas são inibidas pelo pirimicarbo e essa acção foi detectada pelo biossensor, tendo-se determinado uma curva de calibração segundo a recta: $\mathrm{y}=7 \times 10^{6} \mathrm{x}+$ 35.886 com $\mathrm{R}^{2}=0.9622$. 


\section{Biosensor de Acetilcolinesterase - Colina Oxidase para Determinação do Pirimicarbo}

\section{Resumo}

Construiu-se um biossensor para a determinação do pirimicarbo, pela co-imobilização de acetilcolinesterase (AChE) e colina oxidase (ChOx) numa membrana de poliétersulfona modificada. A membrana foi aplicada a um sistema base de eléctrodos da Universal Sensors e monitorizou-se o peróxido de hidrogénio formado quando da adição de acetilcolina (ACh) a um tampão apropriadamente escolhido onde se mergulhou o biossensor.

O peróxido de hidrogénio é o produto da hidrólise da colina, catalisada pela colineoxidase. A colina formou-se pela acção da acetilcolinesterase na acetilcolina. $\mathrm{O}$ pirimicarbo inibe estas reacções e esse facto pode ser usado para determinar a sua concentração. Obteve-se um gráfico de calibração para o pirimicarbo.

\section{Referências}

1. E.A.H. Hall, Biosensors, Open University Press, Cambridge, 1990.

2. J.E. Pearson, A. Gill, P. Vadgama, Ann. Clin. Biochem. 37 (2000) 119-145.

3. M.N. Velasco-Garcia, T. Mottram, Biosystems Engineering 84(1) (2003) 112.

4. I. Palchetti, A. Cagnini, M.D. Carlo, C. Coppi, M. Mascini, A.P.F. Turner, Anal. Chim. Acta 337 (1997) 315-321.

5. http://academic.scranton.edu/faculty/CANNM1/biochemistry/biochemistry module.html

6. F.N. Kok, F. Bozuglu, V. Hasirci, Bios. Bioelectr. 17 (2002) 531-539. 